part in the proceedings and discussions are Sir Alfred Zimmern, Sir Arthur Salter,Lord Lothian, the Warden of All Souls, and Sir Donald Cameron. A number of anthropologists have been invited to join in the diseussions and talks, dealing with problems affecting administration in different regions and from different aspects. About one hundred and seventy officers on leave have intimated their intention of attending the School. Although not 'official', the School has had the cordial support and assistance of the Colonial Office.

\section{An Astronomical Jubilee}

La Soctété Astronomique de France, the creation of Camille Flammarion, who did so much to popularize astronomy in France, has recently celebrated its jubilee. The chief event in the festivities which were held to commemorate the occasion was a great reception on June 16 in the Great Theatre of the Sorbonne, at which nearly three thousand people were present; the President of the French Republic attended and the Minister of Education, M. Jean Zay, presided. M. Jules Baillaud, the present president of the Society, gave an account of the history of the Society and of the work done for it successively by Camille Flammarion and his widow. After a short address by the Minister of Education, Prof. C. Fabry gave a charming account of the progress or revolution in the astronomical outlook in the past fifty years, and some beautiful slides which had been taken by Mr. Ritchey and by M. de Kerolyr at Fourcalquier were shown by M. Baldet. A film was shown of Camille Flammarion's activities in connexion with the Society, and a recorded speech of his was repeated to the audience. A concert followed in which artists from the Opera assisted, while at an earlier stage artists from the Comédie. Française and elsewhere recited poems and read extracts from Camille Flammarion's works. A memorable evening, such as could scarcely have been held anywhere outside Paris, concluded with some ballets danced by pupils of the late Loje Fuller.

THE celebrations were attended by astronomers from Belgium; Czechoslovakia, Denmark, Great Britain, Italy and the United States to add their greetings and congratulations to the Society, its president and its secretary, Madame Camille Flammarion. Opportunity was taken of the presence of many astronomers in Paris for a discussion on various aspects of the problem of interstellar matter in space, which is to be the subject of a conference in Paris on July 11-17 at the Institut HenriPoincaré. Messrs. M. G. Darmois, J. Baillaud, Lacroute, F. Perrin, Chalonge, Barbier and Mineur gave an account of the present state of our knowledge on interstellar calcium, absorption in space, the structure of the galaxy, the nature and distribution of absorbing clouds and their effect on stellar spectra and colour indices.

\section{Covent Garden Laboratory}

For the last eleven years, contact has been min. tained between the work of the Department of
Scientific and Industrial Research on the transport and storage of food and an important branch of industry through the Department's Covent Garden Laboratory in Endell Street, London. This Laboratory has provided an excellent place for keeping under survey the condition of produce passing through our markets generally and for diagnosing or tracing to their source the different types of wastage and deterioration in fruit and vegetables. Samples of fruits showing wastage or abnormal features are collected from the market or are brought to the Laboratory by salesmen. Often the trouble can be diagnosed at once, but sometimes it is desirable to get the diagnosis confirmed by the Low Temperature Research Station at Cambridge or the Ditton Laboratory. The Covent Garden Laboratory also receives for examination samples of consignments of fruits new or comparatively new to Great Britain, such as mangoes, mangosteens and papaws. The interest taken in this work has now made it necessary to leave Endell Street for larger premises, which were opened by Sir Frank Smith on June 28. These are situated on the top floor of Nos. 9-13 Kean Street.

The new accommodation includes two chemical laboratories, a large 'ice box' for cooling fruit to $-30^{\circ} \mathrm{F}$. and three cold stores. One, maintained at $34^{\circ} \mathrm{F}$., will be used for delaying ripening and for observations on apples; another at $45^{\circ} \mathrm{F}$. for work on citrus fruits, and the third at $65^{\circ} \mathrm{F}$. will be used as a conditioning room for initiating ripening. The two colder stores will also be used for studying the advantages of temporary cold storage for wholesalers or retailers, that is, storage of, say, mushrooms and melons for short periods. In the chemical laboratories estimations of the sugar and acid content of the fruit will be carried out. The sugar content of apples, of course, varies between individual specimens, and to get a representative sample the apples are frozen solid and then ground up into a fine powder. Another important measurement to be made is the rate of respiration of the fruit. This not only gives an indication of the age of the apple, but also is important in connexion with research which is being carried out on the mechanism by which sugar breaks down to carbon dioxide. The alcohol content of apples increases as they grow older, and this is also a subject of measurement, as it is hoped that this factor will prove an important diagnostic indication. Produce from the Empire overseas is inspected before being shipped in order that nothing may be exported which is not up to standard. Facilities will be available at the new Laboratory for officers of the Dominions and Colonies engaged in following up this work.

\section{Medicine Stamp Duties}

DUTाEs in respect of medicines were first imposed so far back as 1783. The tax then was twofold, as it is to-day. It was imposed on all persons who sold medicines, not being doctors, apothecaries, ete., and secondly a duty was 'laid on the medicines' themselves when sold by such persons. A Select Committeo 